\title{
The Cannabinoids as Therapeutic Agents in the Management of Pain CD McGaw
}

\begin{abstract}
Objective: This review focussed on the role of the endocannabinoid system in relation to pain transmission and modulation. Various facets of both naturally occurring and synthetic cannabinoids $(C B s)$ were explored in an effort to ascertain their suitability in the treatment and management of pain.

Methods: The endocannabinoid system and the physiology of CBs were reviewed in isolation and in relation to their hypothesized role in treating pain.

Results: Cannabinoids have a more significant effect in instances of chronic pain than acute pain. Inhibitory mechanisms may be more effective than direct activation of the cannabinoid receptors. Many clinical trials of both genuine and synthetic cannabis-mediated analgesia have provided negative or equivocal results.

Conclusion: Medications prepared with cannabinoid receptor agonists or with drugs that enhance endocannabinoid function (by either increasing release or diminishing reuptake of endocannabinoids) may afford the novel therapeutic approaches demanded by disorders in which pain is a prominent symptom.
\end{abstract}

Keywords: Cannabinoids, marijuana, pain, pain management

\section{Los Cannabinoides como Agentes Terapéuticos en el Tratamiento del Dolor CD McGaw}

\begin{abstract}
RESUMEN
Objetivo: Este artículo se centró en el papel del sistema endocannabinoide en relación con la transmisión y la modulación del dolor. Se exploraron varias facetas de los cannabinoides (CB) - tanto naturales como sintéticos - en un esfuerzo por determinar su idoneidad en el tratamiento y manejo del dolor.

Métodos: El sistema endocannabinoide y la fisiología de los CB fueron examinados en aislamiento y en relación con su hipotético papel pujante en el tratamiento del dolor.

Resultados: Los cannabinoides tienen un efecto más significativo en casos de dolor crónico que en el dolor agudo. Los mecanismos inhibitorios pueden ser más efectivos que la activación directa de los receptores cannabinoides. Muchos ensayos clínicos de analgesia - tanto genuina como sintética mediada por cannabis - han proporcionado resultados negativos o equívocos.
\end{abstract}

From: Department of Surgery, Radiology, Anaesthesia and Intensive Care, The University of the West Indies, Mona, Jamaica, West Indies.
Correspondence: Dr C McGaw, Department of Surgery, Radiology, Anaesthesia and Intensive Care, The University of the West Indies, Mona, Kingston 7, Jamaica, West Indies. Email: cdmcgaw@ cwjamaica.com 
Conclusión: Los medicamentos preparados con agonistas del receptor cannabinoide o con fármacos que mejoren la función endocannabinoide (ya sea aumentando la liberación o disminuyendo la recaptación de los endocannabinoides) pueden dar espacio a los enfoques terapéuticos nuevos exigidos por los desórdenes en los que el dolor es un síntoma prominente.

Palabras clave: Cannabinoides, marihuana, dolor, tratamiento del dolor

West Indian Med J 2017; 66 (5): 577

\section{INTRODUCTION}

The cannabinoids and the endocannabinoid system The endocannabinoid system (ECS) is comprised of the cannabinoid receptors (CBRs), their endogenous ligands - N-arachidoylethanolamine (anadamide or AEA) and 2-arachidonoylglycerol (2-AG) - and their metabolizing enzymes. Endocannabinoids modulate pain under physiologic conditions. There are several sites in pain pathways that cannabinoids (CBs) may exert action (1). The midbrain periaqueductal gray (PAG) receives extensive collaterals from the spinothalamic pathway and projects fibres via the rostral ventromedial medulla (RVM) to the spinal cord dorsal horn. These descending pathways may inhibit or facilitate nociceptive transmission. Cannabinoid receptors are found in all nociceptive neuroanatomical pathways and participate in descending supraspinal pain modulation via the PAG and RVM. Cannabinoid receptors are G-protein coupled receptors located on presynaptic neurons. Cannabinoids produce their effects through the activation of these receptors, two of which have been identified, designated $\mathrm{CB}_{1}$ and $\mathrm{CB}_{2}$ receptors $(2,3)$. Delta-9-tetrahydrocannabinol $\left(\Delta^{9}\right.$ THC) acts as an agonist on the $\mathrm{CB}_{1}$ receptors in the central nervous system.

Over many years, numerous anecdotes have emerged claiming efficacy for the use of marijuana in the treatment of a plethora of medical conditions $(4,5)$. These claims have increased with the decriminalization and legalization of medical marijuana in many states of the United States of America and in other countries. The discovery that humans have an ECS that plays a physiological role in the modulation of pain, akin to the endorphin-encephalin system, has fuelled the belief that the $\mathrm{CBs}$ could become a significant addition to the range of therapeutic agents used in the management of pain.

This review focussed on the ECS in relation to pain transmission and modulation alongside some of the important animal and human studies performed in this area to date.

\section{SUBJECTS AND METHODS}

A systematic review of both online and printed resources dealing with the use of CB-related products for treatment of acute postoperative pain and chronic pain states was conducted. For the purpose of this study, acute pain referred to the normal, predicted physiological response to noxious stimuli (chemical, thermal or pressure etc) which threaten to damage normal tissue by causing soft tissue injury or inflammation (6). Chronic pain referred to sustained sensory abnormality occurring as a result of an ongoing peripheral pathology, such as chronic inflammation, or it can be autonomous, independent of the trigger that initiated it (6).

Google Scholar and journals specializing in pain, anaesthesia and pharmacology were the main resources utilized for this review, as well as the references listed in those resources. Keywords used in the searches were: treatment, pain (acute or postoperative, and chronic or neuropathic) and cannabinoids. Included were recent studies of high quality, especially those with randomized controlled study designs. Most of them were from 2000 onwards. Excluded were outcomes based on anecdotal evidence or derived from poor-quality studies. While approximately 30 studies were read, the outcomes from 20 of these studies were utilized for this review.

\section{RESULTS}

Currently available analgesic agents and pain-modulating procedures are severely limited by combinations of low efficacy, excessive toxicity and safety concerns, insufficient access to care, or unbearable cost. Opioids are the usual treatment for moderate to severe postoperative pain, but their clinical effectiveness and usefulness are impeded by undesirable side-effects, such as respiratory 
depression, cognitive impairment, and nausea and vomiting (7).

The use of a multimodal analgesic regimen for the treatment of pain is safer and more efficacious than a unimodal mechanism utilizing high doses of opioids (8). The ECS represents another pathway by which the transmission of nociceptive impulses may be antagonized, and holds out the prospect for selective $\mathrm{CB}$ agonists to become a part of the armamentarium for a multimodal management of pain.

\section{Clinical studies of chronic pain}

Expanding evidence indicates that herbal cannabis and other formulations of cannabis have analgesic effects in both neuropathic and non-neuropathic pain $(9,10)$. The most robust evidence exists for neuropathic pain, and there are a number of high-quality randomized controlled clinical trials establishing the analgesic efficacy of smoked cannabis $(11,12)$.

In an attempt to meet the rigorous standards of the US Food and Drug Administration, synthetic CBs have been formulated for clinical trials and administration to patients. Some of the synthetic CBs on which clinical trials have been conducted include dronabinol, nabilone and ajulemic acid. Oral dronabinol, a synthetic THC compound in sesame oil, is marketed in synthetic form as Marinol (Solvay Pharmaceutical) and was originally approved in 1985 for the treatment of nausea and vomiting associated with cancer chemotherapy. However, oral dronabinol's expense, variability of action, and attendant intoxication and dysphoria have limited its adoption by clinicians (13). Oral absorption of tetrahydrocannabinol is slow and erratic, with peak serum levels in 45-120 minutes or longer. Systemic bioavailability is also quite low due to rapid hepatic metabolism on first pass to 11-hydroxy-THC.

Nabilone (Cesamet, Valeant Pharmaceutical International) is a synthetic molecule that is similar to, but more potent than, THC (14). Primarily developed as an antiemetic in chemotherapy, case reports evidence its analgesic effects in treating neuropathic pain and other pain disorders $(15,16)$.

Cannador is an encapsulated oral cannabis extract with variable tetrahydrocanabinoid:cannabidiol ratios (17). In a Phase III randomized, controlled trial employing cannador in spasticity in multiple sclerosis, no improvement was noted on the Ashworth Scale, but benefit was observed in spasm-associated pain on subjective measures (18). In 30 postoperative pain subjects without opiates, cannador showed slight benefits, but also prominent psychoactive side-effects, including sedation and a vasovagal syncope (19).

Sativex (GW Pharmaceuticals) is an oromucosal, whole cannabis-based spray combining a $\mathrm{CB}_{1}$ partial agonist (THC) with a cannabinoid system modulator (CBD), minor CBs and terpenoids. Being an oromucosal spray, it is not associated with irritation of the lung and other adverse consequences of inhaled smoke. It has been approved in Canada as an adjunctive treatment for the symptomatic relief of neuropathic pain in multiple sclerosis and in cases of cancer pain unresponsive to optimized opioid therapy. The most studied of the CB products, sativex has been observed in over 2500 patient years of exposure in over 2000 experimental subjects. It has a very favourable adverse event profile: cannabidiol is a non-psychoactive analgesic with anti-inflammatory properties that counteracts some adverse effects associated with THC (17). The analgesic effects were not always clearly visible in these studies (20). While its efficacy in the treatment of painful diabetic peripheral neuropathy was unimpressive, it showed more positive results compared with placebo or other CB products in studies involving patients with peripheral and central neuropathic pain (21-23). As for treatment-related adverse effects, the most frequently observed in the THC/CBD oromucosal spray group were dizziness, nausea, vomiting, dry mouth, somnolence and confusion.

Ajulemic acid (CT-3) is a synthetic CB derivative that binds to the $\mathrm{CB}_{1}$ receptor and has shown analgesic and anti-inflammatory properties in animal models (24). One small trial of ajulemic acid versus placebo in neuropathic pain favoured ajulemic acid (25).

\section{Clinical studies of acute pain}

The few clinical trials on the use of CBs in the treatment of postoperative pain have produced mixed and varied results. In a randomized, placebo-controlled study, the $\mathrm{CB}$, levonantradol, provided non-dose-dependent pain relief, though the study was limited as a result of adverse side-effects (26). However, a study of $5 \mathrm{mg}$ of dronabinol versus placebo in postoperative pain following abdominal hysterectomy revealed no evidence of an analgesic effect of the agent (27).

Holdcroft et al conducted a dose-escalation study of the postoperative pain-relieving qualities of oral cannabis, Cannador $^{\mathbb{R}}$ (19). For postoperative pain, a THC-cannabidiol mixture offers the potentially distinctive role of analgesia and anti-inflammatory effects as well as relief of muscle spasm, reduction of nausea and vomiting, and appetite stimulation. It may thus support 
postsurgical recovery without adverse effects such as respiratory depression, renal failure or gastrointestinal ulceration. Cannador was given after a variety of postsurgical patients requiring overnight patient-controlled analgesia (PCA) with morphine stopped using their PCA, and at a point where oral analgesic administration was clinically indicated. Each patient received a single dose of 5,10 or $15 \mathrm{mg}$ of cannador if he or she had at least moderate pain after stopping PCA. The low dose of $5 \mathrm{mg}$ had no demonstrable clinical effects, but the two higher doses reduced demands and extended time lag for rescue analgesia. Rescue analgesia was requested by all 11 patients (100\%) who received $5 \mathrm{mg}, 15$ of 30 patients $(50 \%)$ who received $10 \mathrm{mg}$, and 6 of 24 patients $(25 \%)$ who received $15 \mathrm{mg}$. The optimal dose was determined to be $10 \mathrm{mg}$ of cannador because it was effective in providing pain relief at rest without serious or severe side-effects in a fit adult group of postsurgical patients.

\section{DISCUSSION}

Basic research on the ECS and its interactions with the body's pain pathways are progressing apace. However, the production of effective, safe and clinically viable formulations remain elusive. A large body of anecdotal information has accumulated over many years to support the use of CBs for the treatment of pain (5). Nonetheless, it has not been until recently that a few controlled clinical trials have been conducted on this topic. Many clinical trials of both genuine and synthetic cannabis-mediated analgesia have provided negative or equivocal results. One interesting observation is that studies involving patients with chronic pain states (eg neuropathic pain) have yielded more positive results than those with acute pain states (eg postoperative pain). Nevertheless, a fundamental physiological role in nociception has been demonstrated, and advances in cannabis research have ensured a future for these analgesic molecules. Medications prepared with CBR agonists or with drugs that enhance endocannabinoid function (by either increasing release or diminishing reuptake of endocannabinoids) may afford the novel therapeutic approaches demanded by disorders in which pain is a prominent symptom.

Pharmacologic manipulation directed to elevate levels of endocannabinoids (such as with anandamide reuptake inhibitors or by inhibiting the enzyme fatty acid amide hydrolase, which is responsible for intracellular anandamide degradation) may well become a valuable therapeutic tool. Cannabinoid $\mathrm{CB}_{2}$ receptor selective agonists with no central effects are other promising pain treatment agents under investigation. Inhibition of deactivation of endocannabinoids is likely to show a more beneficial and circumscribed spectrum of biological effects compared to direct activation of $\mathrm{CB}_{1}$ receptors.

\section{Methods of use and administration}

Cannabis can be self-administered by smoking, vaporization, eating, orally applied tinctures, and topical application as salves. Smoked or vaporized cannabis is more rapid in onset than other routes of administration. With the onset of effects experienced within minutes, this allows for rapid titration of effects for pain and other symptom management, alongside psychotropic effects. There are devices under study that would provide metered doses of vaporized cannabis (28).

\section{Toxicity}

Cannabis has very low potential for overdose and relatively low rates of addiction and harmful use compared to opioid analgesics and may clinically replace opioids in some contexts, thus reducing opioid-related harm. Cannabinoids have a very high therapeutic index. It is virtually unlimited, insofar as fatalities have not been reported directly related to the toxicity of any cannabinoid, even with extremely high dosing. Nonetheless, there are potentially severe cognitive, psychotomimetic and substance abuse-related adverse effects associated with $\Delta^{9}$-THC exposure that must be taken seriously, especially in young or cannabis-naïve patients (29).

\section{CONCLUSION}

Cannabinoids have antinociceptive mechanisms different from those of other drugs currently in use. This opens a new line of promising treatment to mitigate pain that fails to respond to the pharmacologic treatments available, especially for neuropathic and inflammatory pains. The distribution of CBRs provides an anatomical basis for the analgesic effects of the CBs. The combination of CBs with synergistic analgesic substances is interesting because it may improve the efficacy and safety of treatment.

Crude cannabis is unlikely to be approved by the US Food and Drug Administration as a prescription medicine due to a lack of rigorous standardization of the drug, an absence of Phase III clinical trials, and pulmonary sequelae (bronchial irritation and cough) associated with smoking. More research is needed to understand fully the ideal CB and other active cannabis constituent content and ratios for effective analgesia in different types of pain and other symptom management. There is some 
uncertainty regarding the relative analgesic actions of different components of herbal cannabis. Nonetheless, there is evidence which supports THC and CBD (the two CBs typically in highest concentration in herbal cannabis) being potentially useful analgesics (30).

\section{REFERENCES}

1. Hosking RD, Zajicek JP. Therapeutic potential of cannabis in pain medicine. Br J Anaesth 2008; 101: 59-68.

2. Howlett AC, Johnson MR, Melvin LS, Milne GM. Nonclassical cannabinoid analgetics inhibit adenylate cyclase: development of a cannabinoid receptor model. Mol Pharmacol 1988; 33: 297-302.

3. Munro S, Thomas KL, Abu-Shaar M. Molecular characterization of a peripheral receptor for cannabinoids. Nature 1993; 365: 61-5.

4. Li H-L. An archaeological and historical account of cannabis in China. Econ Bot 1973; 28: 437-48.

5. Grinspoon L, Bakalar JB. Marihuana, the forbidden medicine. New Haven: Yale University Press; 1997.

6. Basbaum Al, Bautista DM, Scherrer G, Julius D. Cellular and molecular mechanisms of pain. Cell 2009; 139: 267-84.

7. Sintra R. Review article: causes and consequences of inadequate management of acute pain. Pain Medicine 2010; 11: 1859-71.

8. Kehlet H, Dahl JB. The value of "multimodal" or "balanced analgesia" in postoperative pain treatment. Anesth Analg 1993; 77: 1048-56.

9. Lynch ME, Campbell F. Cannabinoids for treatment of chronic non-cancer pain; a systematic review of randomized trials. Br J Clin Pharmacol 2011; 72: 735-44.

10. Lynch ME, Ware MA. Cannabinoids for the treatment of chronic noncancer pain: an updated systematic review of randomized controlled trials. J Neuroimmune Pharmacol 2015; 10: 293-301.

11. Abrams DI, Jay CA, Shade SB, Vizoso H, Reda H, Press S et al. Cannabis in painful HIV-associated sensory neuropathy: a randomized placebo-controlled trial. Neurology 2007; 68: 515-21.

12. Ware MA, Wang T, Shapiro S, Robinson A, Ducruet T, Huynh T et al. Smoked cannabis for chronic neuropathic pain: a randomized controlled trial. CMAJ 2010; 182: E694-701.

13. Attal N, Brasseur L, Guirimand D, Clermond-Gnamien S, Atlami S, Bouhassira D. Are oral cannabinoids safe and effective in refractory neuropathic pain? Eur J Pain 2004; 8: 173-7.

14. British Medical Association. Therapeutic uses of cannabis. Amsterdam, The Netherlands: Harwood Academic Publishers; 1997: 11.

15. Notcutt W, Price M, Chapman G. Clinical experience with nabilone for chronic pain. Pharmaceutical Sciences 1997; 3: 551-5.

16. Berlach DM, Shir Y, Ware MA. Experience with the synthetic cannabinoid nabilone in chronic noncancer pain. Pain Med 2006; 7: 25-9.
17. Russo EB, Guy GW. A tale of two cannabinoids: the therapeutic rationale for combining tetrahydrocannabinol and cannabidiol. Med Hypotheses 2006; 66: 234-46.

18. Zajicek J, Fox P, Sanders H, Wright D, Vickery J, Nunn A et al. Cannabinoids for treatment of spasticity and other symptoms related to multiple sclerosis (CAMS study): multicentre randomised placebocontrolled trial. Lancet 2003; 362: 1517-26.

19. Holdcroft A, Maze M, Dore C, Tebbs S, Thompson S. A multicenter dose-escalation study of the analgesic and adverse effects of an oral cannabis extract (Cannador) for postoperative pain management. Anesthesiology 2006; 104: 1040-6.

20. Selvarajah D, Gandhi R, Emery CJ, Tesfaye S. Randomized placebocontrolled double-blind clinical trial of cannabis-based medicinal product (Sativex) in painful diabetic neuropathy: depression is a major confounding factor. Diabetes Care 2010; 33: 128-30.

21. Notcutt W, Price M, Miller R, Newport S, Phillips C, Simmons S et al. Initial experiences with medicinal extracts of cannabis for chronic pain: results from 34 "N of 1" studies. Anaesthesia 2004; 59: 440-52.

22. Rog DJ, Nurmikko TJ, Friede T, Young CA. Randomized, controlled trial of cannabis-based medicine in central pain in multiple sclerosis. Neurology 2005; 65: 812-9.

23. Nurmikko TJ, Serpell MG, Hoggart B, Toomey PJ, Morlion BJ, Haines D. Sativex successfully treats neuropathic pain characterised by allodynia: a randomised, double-blind, placebo-controlled clinical trial. Pain 2007; 133: 210-20.

24. Burnstein S. Ajulemic acid (IP-751): synthesis, proof of principle, toxicity studies, and clinical trials. AAPS J 2005; 7: E143-8.

25. Karst M, Salim K, Burnstein S, Conrad I, Hoy L, Schneider U. Analgesis effect of the synthetic cannabinoid CT-3 on chronic neuropathic pain: a randomized controlled trial. JAMA 2003; 290: 1757-62.

26. Jain AK, Ryan JR, McMahon FG, Smith G. Evaluation of intramuscular levonantradol and placebo in acute postoperative pain. J Clin Pharmacol 1981; 21: 320S-326S.

27. Buggy DJ, Toogood L, Maric S, Sharpe P, Lambert DJ. Lack of analgesic efficacy of oral delta-9-tetrahydrocannabinol in postoperative pain. Pain 2003; 106: 169-72.

28. Eisenberg E, Ogintz M, Almog S. The pharmacokinetics, efficacy, safety, and ease of use of a novel portable metered-dose cannabis inhaler in patients with chronic neuropathic pain: a phase 1a study. J Pain Palliat Care Pharmacother 2014; 28: 216-25.

29. Malone DT, Hill MN, Rubino T. Adolescent cannabis use and psychosis: epidemiology and neurodevelopmental models. Br J Pharmacol 2010; 160: $511-22$.

30. Savage SR, Romero-Sandoval A, Schatman M, Wallace M, Fanciullo G, McCarberg B et al. Cannabis in pain treatment: clinical and research considerations. J Pain 2016; 17: 654-68. 